\title{
Thermal performance analysis of a tilted single glazed flat plate collector considering the effect of clear sky black body temperature under different ambient conditions encountered in Delhi.
}

Sachin Kumar ( $\square$ skmtech11@gmail.com )

SKITM: Sat Kabir Institue of Technology and Management https://orcid.org/0000-0002-3368-4846

\section{Research Article}

Keywords: Effective black body sky temperature, overall heat loss coefficient, environment conditions, and Collector efficiency

Posted Date: February 2nd, 2022

DOI: https://doi.org/10.21203/rs.3.rs-852905/v1

License: (9) This work is licensed under a Creative Commons Attribution 4.0 International License. Read Full License

Version of Record: A version of this preprint was published at Heat Transfer Research on January 1st, 2022. See the published version at https://doi.org/10.1615/HeatTransRes.2022040330. 


\section{Abstract}

The present study concerns with the thermal analysis of a flat plate collector covered with a single glass having a tilted surface facing south, located at Delhi ( $\left.28^{\circ} 64^{\prime} \mathrm{N}, 77^{0} 12^{\prime} \mathrm{E}\right)$, India under different operating and climate conditions. Solar radiations falling on the tilted surface were noted throughout the year and based on the availability of these solar radiations optimum tilt angle was estimated by using empirical relation for every month of a year. The lowest optimum tilt angle was estimated for June $\left(5.26^{\circ}\right)$, and the highest was estimated for December $\left(51.95^{\circ}\right)$ with an overall optimum tilt angle of $31.1^{0}$ for a year. The maximum variation in estimated values of $U_{\mathrm{L}}$ is $11 \%$ and the collector heat efficiency factor has a maximum variation of $1.24 \%$ to $2.52 \%$. Further, the use of the Swinbank equation provides the lower value of heat loss which in turn provides the highest value of useful heat gain and thus the efficiency is $4.596 \%$ to $9.94 \%$ higher than the efficiency calculated by using Angstrom relation which gives the lowest value of efficiency.

\section{Introduction}

Increase in global population has increased demand in energy consumption at building sectors for applications such as space heating, lighting, etc., and production of this excess amount of energy has become a matter of concern as in recent time availability of fossil fuels such as natural gas, coal, etc has been reduced due to which supply of this excess amount of electrical energy to building sectors looks like a challenging task to fulfill the customer's demand. Moreover, the consumption of fossil fuels to produce electricity also harms the environment and causes global warming. That's why finding an alternate source of energy that is less hazardous to the environment has become necessary.

Solar energy, a renewable kind of energy, available free at every place on earth, is the source of energy that causes no environmental hazards and also easy to be convertible into electrical energy. Flat plate collectors are the most popular devices to collect solar radiations for producing heating effects to heat water for building sectors. FPC is the kind of heat exchanger in which heat is transfer to working fluid by collecting solar radiations. These are simple to construct as well as install and have a low maintenance cost. Besides these advantages, the main drawback of FPC is its poor thermal efficiency because of low density and larger exposed surface area for heat loss to the surrounding.

While designing any kind of energy storage device, engineers must reduce heat loss for better performance. Many kinds of research have been done in reducing the major heat loss, in turn, to increase the thermal performances of FPC. The efficiency of FPC can be increased by coating the collector with several selected coaters. FPC with selective coaters has improved thermal performance as compared to black-coated FPC due to an increase in average temperature obtained by chrome-coated surface as compared to the black-coated surface (Shrestha et al. 2021). Use of carbon-coated absorber plate can give up to $35.04 \%$ higher efficiency as compared to black-chrome coated and up to $28.4 \%$ higher efficiency as compared black-painted absorber plate due to reduction in heat removing parameters (Sakhaei and Valipour 2020) 
Further, the implementation of a corrugated riser with reduced pitch length and with little increment in roughness height can also increase the thermal performances of FPC (Sayed Ali Sakhaei et al. 2020). Also, helically corrugated risers provide lesser less heat loss to the surrounding as compared to conventional tube arrangement (Sayed Ali Sakhaei et al. 2020). Muhammad Asmail Eleiwi et al. (2020) used a ' $V$ ' shaped corrugated absorber plate with implementations of heat exchanger which reduces the fuel consumption by $65 \%$. The collector efficiency can be enhanced by using a reflector on the top surface due to which more amount of solar radiations are concentrated on the absorber plate which increases the efficiency up to 9\% (Himangshu Bhowmik et al. 2017). Many researchers have used nanoparticles as working fluid, especially at low temperatures to increase the thermal performances of FPC. The use of nanoparticles increases useful heat gain and reduces heat loss which increases thermal efficiency.

The Concentration of nanoparticles also influences the efficiency up to a peak value after which the effect is reversed (A. A. Hawwash et al. 2021) By taking $15 \%$ of Alumina-Water nanofluid, useful heat gain can be increased up to $8.2 \%$ with $4 \%$ reductions in overall heat loss (M. Y. Hussain et al. 2019). By increasing the tube diameter ratio and the number of revolutions of tubes, a larger pressure drop was achieved with a greater Nusselt number, which enhances the thermal performances of FPC (Farshad et al. 2019). FPC with Aluminium Oxide - Water nanoparticles and Copper Oxide-Water nanoparticles as working was tested experimentally by using different shapes of flow paths to pass nanofluid viz; (i) Ushaped, (ii) Spiral pipes, and (iii) Wavy pipes. The use of nanofluid increases heat transfer rate and provides larger pressure drop with increased Nusselt number by using wavy shaped pipes, as flow passage, as compare to U-shaped and Spiral shaped pipes (Mohammad Reza Saffarian et al. 2020). Use of Copper Oxide- Water combination and Magnesium Oxide-Water combination as nanofluid give $5 \%$ and 9\% higher efficiency, respectively, as compared to simple water as working fluid (Nang Khin et al. 2017; Sujit Kumar Verma et al. 2016). Another approach to increasing the thermal efficiency of FPC is to replace water with supercritical Carbon dioxide as a working fluid which enhances the efficiency of FPC (Jahar Sarkar 2013).

Another factor on which the efficiency of FPC depends is its heat transfer coefficient between working fluid and absorber plate. The heat transfer coefficient of FPC can be increased by using intermittent porous blocks and phase change materials (K. Anirudh et al. 2020; Badiei et al. 2020). An experimental study in comparison to theoretical analysis of solar air flat plate collector was conducted at Biskara, Algeria (Kamel Aoues et al. 2011). The comparison test reveals that the use of obstacles in a dynamic vein provides satisfactory results in the thermal performances of solar air flat plate collectors.

Many kinds of research have been done to improve the efficiency of FPC. It has been found that a single glazed FPC provides more efficiency as compared to an unglazed and further it can be improved by double glazing the FPC which causes a reduction in heat loss to the surrounding (H. Vettrivel et al. 2017). Another passive method of increasing thermal efficiency is to increase the convective heat transfer rate between the absorber plate and working fluid with minimum pressure drop. It can be achieved by using a velocity enhancer of both kinds viz; rod and tube. The velocity enhancers work on minimum input power 
with the very low-pressure drop which further results in increased overall performances (K. Balaji, et al. 2017). The higher outlet temperature of working fluid can be obtained by attaching fins to FPC (Ali Daliran and Yahya Ajabshirchi 2018).

Dimitrios N. Korres et.al.(2019) simulated the serpentine flow conduit, both experimentally and theoretically, and predicts that an increase in inclination angle results in less area for convective heat loss inside the tube's gap and efficiency increases. Besides these advantages, the use of multiple riser tubes in FPC cause increased exposed surface area for heat loss, which is a major drawback with its complex design. To reduce the complexity of the circuit, multiple numbers of riser tubes were replaced by a single spiral-shaped tube collector (Sujit Kumar Verma et al. 2019)

The above literature reveals about performance enhancement of collector. For having better thermal efficiency, the energy loss from the top surface of the collector must be minimized. This can be done by glazing and double glazing the FPC or by other ways which have been discussed in the above literature. Many researchers have undertaken many parameters for their studies to reduce heat loss of FPC but none have discussed the effect of varying environmental conditions in calculating thermal losses of FPC which are also get affected by clear sky emissivity. Many authors have provided a relation for clear sky black body temperature under different ambient conditions (Angstrom 1915; Brunt 1932; Swinbank 1963; Berger and Burrito 1964).

The clear sky emissivity or in turn effective clear sky black body temperature affects the convective heat transfer coefficient and also in turn overall heat loss coefficient of FPC. In the present work, the effect of the clear sky black body temperature on thermal performances of single glazed FPC situated in Delhi $\left(28.7041^{\circ} \mathrm{N}, 77.1025^{\circ} \mathrm{E}\right)$, India, will be calculated theoretically by using empirical correlations of clear sky emissivity with different ambient conditions provided by authors.

\section{Mathematical Modeling}

A liquid flat collector consists of an absorber plate that absorbs all short wave solar radiations and transfers this amount of heat energy to liquid circulating through tubes or other kinds of flow channels installed inside the absorber plate. This heat energy transferred to liquid is known as the useful heat gain of a flat plate collector. In the present study, a single glazed flat plate collector, as shown in Fig. 1, is considered for the estimation of thermal performances considering the effect of black body sky temperature estimated by the equations proposed by different authors as discussed in the literature. There are three kinds of heat loss to surrounding for a flat plate collector viz; heat transfer from the bottom surface, heat transfer from the top surface, and heat transfer from the side surface. Heat loss from bottom and side surfaces can be reduced by providing insulation effectively, which is not possible for top surface heat loss reduction, which, contributes as a major area of energy loss.

\subsection{Calculations of Solar Radiations:-}


In the present study, a flat plate collector facing south is taken for analysis at Delhi $\left(28^{0} 64^{\prime} \mathrm{N}, 77^{0} 12^{\prime} \mathrm{E}\right)$. Solar radiations falling on flat plate collector were analyzed using empirical relation given by Liu and Jordan (1963), in which total radiations falling on collector are considered as a sum of diffused and beam radiations and given as:

$I_{T}=I_{b} \times R_{b}+I_{d} \times(1+\cos \beta) / 2+\left(I_{b}+I_{d}\right) \times \rho_{g} \times(1-\cos \beta) / 2(1)$

Where the value of $\rho_{g}$ (Diffused ground reflectance factor) is taken as 0.2 for simplification and $R_{b}$, known as tilt factor, is the ratio of Cosine of "Incidence angle $(\theta)$ " to the Cosine of "Zenith angle $(\theta z)$ " and is given as:

$\mathrm{R}_{\mathrm{b}}=(\operatorname{Cos} \theta / \operatorname{Cos} \theta \mathrm{z}) \cdot(2)$

Whereas the incidence angle made by incident solar radiations with normal to the plane surface of collector is given as:

$\operatorname{Cos} \theta=\operatorname{Sin} \varphi(\operatorname{Sin} \delta \operatorname{Cos} \beta+\operatorname{Cos} \delta \operatorname{Cos} \gamma \operatorname{Cos} \omega \operatorname{Sin} \beta)+\operatorname{Cos} \varphi(\operatorname{Cos} \gamma \operatorname{Cos} \omega \operatorname{Cos} \beta-\operatorname{Sin} \delta \operatorname{Cos} \gamma \operatorname{Sin} \beta)$

$+\operatorname{Cos} \gamma \operatorname{Sin} \gamma \operatorname{Sin} \omega \operatorname{Sin} \beta(3)$

As the flat plate collector is facing south so the "Surface Azimuth angle, ' $y$ '," equals zero and the above equation become:

$\operatorname{Cos} \theta=\operatorname{Sin} \delta \operatorname{Sin}(\varphi-\beta)+\operatorname{Cos} \delta \operatorname{Cos} \omega \operatorname{Cos}(\varphi-\beta)(4)$

Here angle ' $\delta$ ' is the declination angle and calculated by the relation given by Cooper [30] as

$\delta^{0}=23.45 \operatorname{Sin}([\{360 \times(284+n)\} / 365])(5)$

And $\varphi$ is the latitude angle having a value equals to $28.64^{\circ}$ for Delhi. Hour angle ' $\omega$ ' is given by the relation:

$\omega=[\{(1200 h-L A T) \times 15\} / 60] .(6)$

The Zenith Angle ( $\theta z)$ can be calculated by putting $\beta=0$ in Eq. (4) and can be written as:

$\operatorname{Cos} \theta z=\operatorname{Sin} \delta \operatorname{Sin} \varphi+\operatorname{Cos} \delta \operatorname{Cos} \omega \operatorname{Cos} \varphi(7)$

\subsection{Estimation of Optimum Tilt Angle:-}

For analyzing the maximum amount of solar radiation falling on the flat plate collector, it is necessary to find the value of the optimum tilt angle. In the present study, the variation of clear sky temperature is being considered which value changes seasonally in India, thus the optimum value of tilt angle ' $\beta$ ' also changes significantly and given by the relation (Sukhatme and Nayak 2013) 
$\beta_{\text {opt }}=\operatorname{Tan}^{-1}\left[\left\{\sum \mathrm{I}_{\mathrm{b}} \times \operatorname{Tan}(\varphi-\delta)\right\} / \sum \mathrm{I}_{\mathrm{b}}\right](8)$

\subsection{Estimation of top heat loss coefficient:-}

Different authors have proposed relations for estimation of top heat loss (S. A. Klein 1975; Agarwal and Larson 1981; Malhotra and Garg 1981; Mullick and Samdarshi 1988). In the present work, the top heat loss is estimated considering the effect of clear sky temperature and is given as (Mullick and Samdarshi 1988):-

$\left(\mathrm{U}_{\mathrm{t}}\right)^{-1}=\left(\mathrm{h}_{\mathrm{rg}-\mathrm{a}}+\mathrm{h}_{\mathrm{w}}\right)^{-1}+\left(\mathrm{h}_{\mathrm{rp}-\mathrm{g}}+\mathrm{h}_{\mathrm{cp}-\mathrm{g}}\right)^{-1}+\left(\mathrm{t}_{\mathrm{g}}\right) / \mathrm{K}_{\mathrm{g}}(9)$

Radiative heat transfer coefficient between glass cover and plate is given as:

$\left(h_{r p-g}\right)=\sigma\left[\left(T_{p}\right)^{2}+\left(T_{g}\right)^{2}\right] \times\left[\left(T_{p}\right)+\left(T_{g}\right)\right]$

$\left[\left(1 / \epsilon_{p}+1 / \epsilon_{g}\right)-1\right](10)$

And $\mathrm{h}_{\mathrm{rg}-\mathrm{a}}$ is given as:

$\left(h_{r g-a)}=\epsilon_{g} \sigma \times\left[\left(T_{g}\right)^{4}-\left(T_{s}\right)^{4}\right]\right.$

$\left[T_{g}-T_{a}\right](11)$

Many empirical relations have been proposed by different authors to calculate sky temperature. In 1915, Angstrom (1915) estimated the effect of ambient conditions on clear sky emissivity as:

$E_{s}=\left[0.82-\left(0.25 \times(10)^{-0.168 \times P v}\right)\right](12)$

In 1932, Brunt (1932), relates the clear sky emissivity with vapour pressure considering the effect of various environmental conditions and proposed the following relation:

$E_{s}=\left[0.52+\left(0.065 \times\left(P_{v}\right)^{0.5}\right)\right](13)$

According to Swinbank (1963) the ambient sky temperature is calculated as:

$\mathrm{Ts}=0.0552 *\left(\mathrm{Ta}^{\wedge} 1.5\right)(14)$

Berger (1984) computed spectral sky radiations and the study reveals that the clear sky emissivity is affected by weather conditions as suggested in the following relation:

$E_{s}=\left[0.77+\left(0.0038 \times T_{d p}\right)\right](15)$

In the present work, the effect of clear sky emissivity and thus, ambient sky temperature on energy loss, in term of heat, from the solar panel will be estimated. Further, convection energy loss for plate with glass cover is estimated by following equation: 
$h_{c p-g}=\left[5.78\left(T_{p}-T_{g}\right)^{0.27}\right] /\left[\left(T_{m p-g}\right)^{0.31}\left(L_{p-g}\right)^{0.21}\right](16)$

Where,

$T_{m p-g}=\left(T_{p}+T_{g}\right) / 2(17)$

And,

$\left.T_{g}=T_{a}+h_{w}{ }^{-0.42}\left[0.6336 \epsilon_{p}+\left(T_{p} / 346\right)-0.6547-1.16 \exp \left\{-0.072\left(T_{p}-T_{a}\right)\right\}\right] \times\left(T_{p}-T_{a}\right)\right](18)$

\subsection{Calculation of Overall Heat Loss Coefficient:-}

The overall heat loss coefficient represents the total amount of energy loss occurred in a collector and given as (Sukhatme and Nayak 2013):-

$\mathrm{U}_{\mathrm{L}}=\mathrm{U}_{\mathrm{t}}+\mathrm{U}_{\mathrm{b}}+\mathrm{U}_{\mathrm{S}}(19)$

And $\mathrm{U}_{\mathrm{b}}=\mathrm{K}_{\mathrm{i}} / \mathrm{t}_{\mathrm{b}}(20)$

Where $\mathrm{K}_{\mathrm{i}}$, and $\mathrm{t}_{\mathrm{b}}$ are known as the thermal conductivity of insulation and thickness of insulation respectively.

\subsection{Calculation of Collector Efficiency:-}

The most important measuring tool for designing a energy storage or energy conversion device it its thermal efficiency. In case of a flat plat collector, the efficiency of the collector reveals the ability of the collector to convert maximum amount of the incident solar radiations in useful heat gain. Thus the collector efficiency is given as:-

$\eta=F_{R} Q_{u} / A_{C} I_{T}(21)$

Where, $\mathrm{F}_{\mathrm{R}}$, known as the collector heat removal factor, an important design parameter the thermal resistance, is calculated as:-

$\left.F_{R}=\dot{m} \times C_{P}\left[\left\{1-\exp \left(-\left(F^{\prime} \times U_{L} \times A_{P}\right) / \dot{m} \times C_{P}\right)\right)\right\}\right]$

$\mathrm{U}_{\mathrm{L}} \times \mathrm{A}_{\mathrm{P}}(22)$

Where $F^{\prime}$ is the collector efficiency factor and is calculated as:-

$F^{\prime}=\left(1 / U_{L}\right) / W\left[1 / U_{L}\{D+(W-D) \times \varepsilon\}+\left(1 / \prod \times D \times h_{f}\right)\right](23)$

In the present study, the efficiency of the collector is taken as a function of top heat loss coefficient, or in terms, effective clear sky black body temperature, and heat removal factor.

Thus $\eta=f\left(F_{R}, U_{t}, T_{s}\right)(24)$ 


\section{Result And Discussion}

\subsection{Estimation of total solar radiations and optimum tilt angle:-}

In the present study, a single glazed flat plate collector with a tilted surface situated at Delhi (India) has been considered for studying the effect of environmental conditions encountered throughout the year. India is a multi-season country in which the environmental condition changes very rapidly throughout the year. Due to changes in climate conditions, there is a significant variation in total solar radiations, and hence there is a significant change in total available solar energy for a flat plate collector. In the present study, global, beam, and diffused solar radiations falling on the tilted surface of a flat plate collector located in Delhi with south-facing has been estimated ${ }^{[31]}$ and plotted in Fig. 2. From Fig. 2, it is seen that there are huge variations in the availability of solar radiation throughout the year every month. The optimum tilt angle varies with variation in the availability of solar radiations, thus for simplicity of the research calculations, the optimum tilt angle is estimated for a complete month by using Eq. 8. From Fig. 3 , it is seen that the overall average optimum tilt angle for a whole year is found $31.1^{\circ}$, whereas, the lowest optimum tilt angle is for June month $\left(5.26^{\circ}\right)$ and the highest optimum tilt angle value is calculated for December month $\left(51.95^{\circ}\right)$. As Delhi $\left(28.61^{\circ} \mathrm{N}, 77.23^{\circ} \mathrm{E}\right)$ is a multi-seasonal city located in India, that's why there exist various climate changes which affect the intensity of solar radiations falling on the plate, in regards which the optimum tilt angle for different seasons have also been estimated. There are interesting changes in the values of optimum tilt angle for four distinct seasons viz; winter, spring, summer, and monsoon. For the winter season (Nov to Jan), optimum tilt angle values vary from $47^{0}-$ $52^{0}$, and the average value of the optimum tilt angle for the winter season is found to be $50^{0}$ approx. The values of optimum tilt angle vary from $18.77^{0}-42.2^{0}$ for spring (Feb to April), $5.26^{0}-9.54^{0}$ for summer (May to mid-July), and $15.13^{0}-37.57^{0}$ monsoon (Mid-July to Oct). The average optimum tilt angle value for spring, summer, and monsoon season is equal to $31^{\circ}, 7.34^{\circ}$, and $26.34^{0}$ respectively as shown in Fig. 4.

\subsection{Estimation of overall heat loss coefficient:-}

Due to change in climate conditions like vapor pressure, relative humidity, dew point temperature, etc clear sky emissivity also changes which affect the calculation of effective black body sky temperature, thus there is remarkable variation in the thermal performances of a flat plate collector. It is cleared in the literature that the sky temperature mostly depends upon clear sky emissivity. Figure 5 reveals that with increase in ambient sky temperature, there is significant increase in plate temperature and the total amount of energy loss from the collector increases which means that the overall energy loss, in terms of heat, from the solar plate is directly affected by ambient temperature, or in turns, the clear sky emissivity (Fig. 5). Also, the radiative heat transfer coefficient is also affected by the clear sky emissivity and it is noted that the clear sky emissivity has reverse impact on radiative heat loss coefficient. It is also noted that the use of Angstrom relation for sky temperature results in the highest value of radiative heat 
transfer coefficient and use of Swinbank ${ }^{k}$ relation for $T_{S}$ results in the lowest value of radiative heat transfer coefficient between the glass cover and ambient when the ambient temperature is $318 \mathrm{~K}$ (Fig. 6).

The effect of clear sky emissivity on the total energy loss encountered for the collector was estimated using the relation provided by different authors and from the Fig. 5 , it is clearly seen that the Angstrom relation estimate the maximum heat loss, whereas, Swinbank relation provide the lower value of heat transfer coefficient. As there was approx $11 \%$ variation in the values of heat loss factor estimated by the relation provided by different authors, so, while designing a solar panel for heat utilization direct from the Sun; a designer should estimate the heat loss occurring in flat plate collector using Angstrom relation for better accuracy.

\subsection{Calculation of collector heat removal factor and collector efficiency:-}

For calculating collector efficiency factor, collector heat removal factor, and also collector efficiency, a flat plate collector having inner and outer tube diameter equal to $12.5 \mathrm{~mm}$ and $13.7 \mathrm{~mm}$ respectively with tube pitch equals to $113 \mathrm{~mm}$ has been considered for the study. The mass flow rate of the liquid (water) flowing through the tube passage is taken as $70 \mathrm{Kg} / \mathrm{h}$ and the fluid heat transfer coefficient is taken as $500 \mathrm{~W} / \mathrm{m}^{2}-\mathrm{K}$ for ease of simplification. The collector efficiency factor is a function of the overall heat loss coefficient, which is varying with sky temperature, that's why the collector efficiency factor also varies with clear sky ambient temperature as shown in Fig. 7. From Fig. 7, it is clear that as the sky temperature, or in turn, plate temperature increases, the collector efficiency factors values decreases. The collector efficiency factor has the maximum values when the ambient temperature is being calculated by using Swinbank relation while the use of Angstrom relation gives the lower values of collector efficiency factor. Figure 8 shows the variation of collector heat removal factor with plate temperature considering the effect of clear sky temperature calculated by using the equations provided by different authors as mentioned in the literature. From figure 8, it is noticed that the use of Angstrom relation gives the lowest value while the use of the Swinbank equation gives the highest values of collector heat removal factor. There is approx $1.24 \%$ to $2.52 \%$ variation in the respective lowest and highest values of collector efficiency factor calculated by using Angstrom and Swinbank relation which is a significant variation to be considered. Similarly, the overall collector efficiency calculated by Swinbank relation gives the highest values as compared to others. Use of Swinbank equation for calculating overall heat loss coefficient provides the lower value which in turns provides the highest value of useful heat gain and thus the efficiency is $4.596 \%$ to $9.94 \%$ higher than the efficiency calculated by using Angstrom relation which gives the lowest value of efficiency (Figure 9).

\section{Conclusion}

A tilted single glazed south-facing flat plate collector located in Delhi, India has been considered for studying the effect of clear sky black body temperature on the thermal performance of a flat plate solar collector. The sky temperature has been estimated using correlations provided by different authors as 
mentioned in the literature. From the literature, it is cleared that radiative heat transfer coefficient and top heat loss coefficient values vary with clear sky temperature and thus the overall heat loss coefficient. The solar radiations falling on the surface of flat plate collector has been estimated on monthly basis and it was found that there is huge variation in the availability of solar radiation in different months as Delhi is a multi-seasonal city and there is huge variation in climate conditions in every season due to which there is a variation in the availability of solar radiations. Thus due to these variations in climate conditions, different tilt angle values are estimated for different months and also there is variation in thermal performances of the collector due to change in climate conditions. The main results of the study are:-

i) Due to variation in available solar radiation, the optimum tilt angle has been estimated on monthly basis, as well as, seasonal basis. It was found that the optimum tilt angle has different values for each month. The lowest value of the optimum tilt angle was found to be $5.26^{\circ}$ for June whereas, the highest value of the optimum tilt angle was found to be $51.95^{\circ}$ for December month. The average optimum tilt angle for the whole year was estimated and found to be $31.1^{0}$.

ii) The seasonal variation in the values of optimum tilt angle has been also calculated and it was found that the average value of optimum tilt angle for winter, spring, summer, and monsoon season is $50^{0}, 31^{0}$, $7.34^{\circ}$, and $26.34^{0}$ respectively.

iii) For a selected range of working parameters, the overall heat loss coefficient and heat loss due to radiation between glass and ambient has been estimated, and it was found that there are approx $14 \%$ variations in the values of total energy loss and also the maximum and minimum absolute values of radiative heat transfer between absorber plate and glass cover was found to vary up to $121 \%$ when estimated by using correlations provide by different authors.

iv) With an increase in clear sky temperature, or in turns, plate temperature of flat plate collector, the values of collector heat removal factor and collector efficiency factor decrease. The collector efficiency factor has the maximum values when the ambient temperature is being calculated by using Swinbank relation while the use of Angstrom relation gives the lower values of collector efficiency factor. There is approx $1.24-2.52 \%$ variation in the respective lowest and highest values of collector efficiency factor calculated by using Angstrom and Swinbank relation which is a significant variation to be considered.

v) Use of Swinbank equation for calculating overall heat loss coefficient provides the lower value which in turn provides the highest value of useful heat gain and thus the efficiency is $4.596-9.94 \%$ higher than the efficiency calculated by using Angstrom relation which gives the lowest value of efficiency.

\section{Abbreviations}

a- ambient

c- convection 
FPC - Flat Plate Collector

$\mathrm{F}_{\mathrm{R}}$ - Collector Heat Removal Factor

F' - Collector Efficiency Factor

g- glass

h- Heat Transfer Coefficient $\left(\mathrm{W} \mathrm{m}^{-2} \mathrm{~K}^{-1}\right)$

$\mathrm{I}_{\mathrm{T}}$ - Total Radiations

$\mathrm{I}_{\mathrm{b}}$ - Beam Radiations

$I_{d}$ - Diffused Radiations

$\mathrm{k}=$ Thermal conductivity $\left(\mathrm{W} \mathrm{m}^{-2} \mathrm{~K}^{-1}\right)$

$\mathrm{L}=\operatorname{Air}$ gap $(\mathrm{m})$

LAT - Local Apparent Time

p-Plate

$P_{V}$ - Vapor pressure

r-Radiations

$\mathrm{R}_{\mathrm{b}}$ - Tilt Factor

$\mathrm{RH}$ - Relative humidity

s-Sky

T- Thickness (mm)

$T_{d p}$ - Dew point temperature

$\mathrm{T}$ - Temperature $(\mathrm{K})$

$U_{t}$ - Top heat loss coefficient $\left(\mathrm{W} \mathrm{m}^{-2} \mathrm{~K}^{-1}\right)$

$\mathrm{U}_{\mathrm{b}}$ - Bottom heat loss coefficient $\left(\mathrm{W} \mathrm{m}^{-2} \mathrm{~K}^{-1}\right)$

$\mathrm{U}_{\mathrm{s}}$ - Side heat loss coefficient $\left(\mathrm{W} \mathrm{m}^{-2} \mathrm{~K}^{-1}\right)$ 
$U_{L}$ - Overall heat loss coefficient $\left(\mathrm{W} \mathrm{m}^{-2} \mathrm{~K}^{-1}\right)$

$\beta$ - Tilt Angle

$\beta_{\text {opt }}$ - Optimum Tilt Angle

$\rho_{g}$ - Diffused Ground Reflectance Factor

$\theta$ - Incidence Angle

$\theta z$ - Zenith Angle

Y - Surface Azimuth Angle

$\delta$ - Declination Angle

$\omega$ - Hour Angle

$\varphi$ - Latitude Angle

$\eta-$ Efficiency

$€$ - Emissivity

\section{Declarations}

Ethics approval and consent to participate:- NA

Consent for publication:- NA

Availability of data and materials:- NA

Competing interests:- The authors declare that they have no competing interests.

Funding:- NA

Authors' contributions:- Sachin Kumar, First and Single author of the manuscript, has did the all research work for this topic.

Acknowledgements:- NA

\section{References}

1. Hawwash AA, Ahamed M, Nada SA, Radwan A, Abdel-Rahman AK, "Thermal Analysis of Flat Plate Solar Collector Using Different Nanofluid and Nanoparticles Percentages" in IEEE Access, vol. 9, pp. 52053-52066, 2021, doi: 10.1109/ACCESS.2021.3060004 
2. Malhotra A, Garg HP, Patil A (1981) Heat loss calculation of flat-plate solar collectors. Journal of Thermal Engineering (Journal of Indian Society of Mechanical Engineers) 2(2):59-62. https://doi.org/10.1016/0038-092X(84)90058-6

3. Daliran A, Yahya Ajabshirchi; "Theoretical and Experimental Research on Effect of Fins Attachment on Operating Parameters and Thermal Efficiency of Solar Air Collector". Information Processing in Agriculture Volume 5, 4, December 2018, 411-421. https://doi.org/10.1016/j.inpa.2018.07.004

4. Angstrom A Knutsson and Smithsonian institution. Hodgkins, fund. 1915. "A study of the radiation of the atmosphere, based upon observations of the nocturnal radiation during expeditions to Algeria and to California." Smithsonian Miscellaneous Collections. 65 (3):1-159

5. Brunt D (1932) Notes on radiation in the atmosphere. Q J R Meteorol Soc 58(247):389-420. https://doi.org/10.1002/qj.49705824704

6. Berger $X$, Burrito $D$ (1984) About the equivalent radiative temperature for clear skies. Sol Energy 32:pp, 725-733. https://doi.org/10.1016/0038-092X(84)90247-0

7. Cooper, P. I., "The absorption of radiation in solar stills", Solar Energy, vol.12, pages 333-346, 1969. https://doi.org/10.1016/0038-092X(69)90047-4.

8. Liu, B.Y.H., Jordan, R.C., "The long term average performance of flat plate solar energy collectors", Solar Energy, vol. 7, pages 53-74, 1963. https://doi.org/10.1016/0038-092X(63)90006-9.

9. Dimitrios Korres., Christos Tzivanidis; " Thermal analysis of a Serpentine Flat Plate Collector and investigation of the flow and convection regime". Thermal Science 2019 Volume 23, Issue 1, Pages: 47-59. https://doi.org/10.2298/TSCl161130172K.

10. Farshad SA, Sheikholeslami M, Hosseini SH et al (2019) Nanofluid turbulent forced convection through a solar flat plate collector with Al2O3 nanoparticles. Microsyst Technol 25:4237-4247. https://doi.org/10.1007/s00542-019-04430-2

11. Vettrivel. H, Mathiazhagan P; "Comparison Study of Solar Flat Plate Collector with Single and Double Glazing Systems". International journal of renewable energy research, Vol.7, No.1, 2017

12. Himangshu B, Ruhul A (2017) Efficiency improvement of flat plate solar collector using reflector. Energy Reports 3:119-123. https://doi.org/10.1016/j.egyr.2017.08.002

13. Jahar S (2013) Performance of a flat-plate solar thermal collector using supercritical carbon dioxide as heat transfer fluid. Int J Sustain Energ 32(6):531-543. https://doi.org/10.1080/14786451.2013.833205

14. Anirudh K., Dhinakaran S (January 2020) Performance improvement of a flat-plate solar collector by inserting intermittent porous blocks. Renewable Energy Volume 145:428-441. https://doi.org/10.1016/j.renene.2019.06.015

15. Balaji K, Iniyan S (January 2018) Ranko Goic; "Thermal performance of solar water heater using velocity enhancer". Renewable Energy 115:887-895. https://doi.org/10.1016/j.renene.2017.09.014

16. Kamel Aoues N, Moummi MZ, Adel Benchabane (2011) Thermal performance improvement of solar air flat plate collector: a theoretical analysis and an experimental study in Biskara, Algeria. Int J Ambient Energy 32(2):95-102. DOI:10.1080/01430750.2011.584469 
17. M. Y. Hussain, H. M. Ali, M. Aneeq, K. A. Sheikh and S. Rehman, "Optical and Thermal Analysis of a Flat Plate Solar Collector Using Water and Alumina Nano Fluids," 2019 International Conference on Applied and Engineering Mathematics (ICAEM), 2019, pp. 139-144, doi:

10.1109/ICAEM.2019.8853749.

18. Mohammad R, Mojtaba S, Hossein MMohammad (February 2020) Doranehgard.; "Heat transfer enhancement in a flat plate solar collector with different flow path shapes using nanofluid". Renewable Energy Volume 146:2316-2329. https://doi.org/10.1016/j.renene.2019.08.081

19. Muhammad Asmail Eleiwi \& Huthaifa Salahuddin Shallal (2020) Thermal Performance of Solar Air Heater Integrated with Air-Water Heat Exchanger Assigned for Ambient Conditions in Iraq. Int $\mathrm{J}$ Ambient Energy. https://doi.org/10.1080/01430750.2020.1722745

20. Nang K, Sint C., Choudhury. IA, Masjuki. HH (October 2017) H.Aoyama; Theoretical analysis to determine the efficiency of a CuO-water nanofluid based-flat plate solar collector for domestic solar water heating system in Myanmar". Solar energy 155:608-619. https://doi.org/10.1016/j.solener.2017.06.055

21. Klein SA, "Calculation of flat-plate collector loss coefficients", Solar Energy, Volume 17, Issue 1, 1975, Pages 79-80, ISSN 0038-092X, https://doi.org/10.1016/0038-092X(75)90020-1

22. Sakhaei SA, Valipour MS (2020) Investigation on the effect of different coated absorber plates on the thermal efficiency of the flat-plate solar collector. J Therm Anal Calorim 140:1597-1610. https://doi.org/10.1007/s10973-019-09148-x

23. Sakhaei SA, Valipour MS, "Thermal performance analysis of a flat plate solar collector by utilizing helically corrugated risers: An experimental study". Solar Energy,Volume207, 1 September 2020, Pages 235-246. https://doi.org/10.1016/j.solener.2020.06.023

24. Mullick SC, Samdarshi SK (1988) An improved technique for computing the top heat loss factor of a flat plate collector with a single glazing. ASME J Sol Energy Eng Vol 110:262-267. https://doi.org/10.1115/1.3268266

25. Shrestha S, Acharya D (2021) Thermal Analysis of the Flat Plate Collectors. North American Academic Research 4(2):311-319 http://doi:https://doi.org/10.5281/zenodo.4573025

26. Verma SK, Sharma K, Gupta NK, Soni P, Neeraj Upadhyay; “Performance comparison of innovative spiral-shaped solar collector design with conventional flat plate solar collector". Energy, Volume 194, 1 March 2020, 116853. https://doi.org/10.1016/j.energy.2019.116853

27. Sujit Kumar Verma., Arun Kumar Tiwari., Durg Singh Chauhan; "Performance augmentation in flat plate solar collector using MgO/water nanofluid". Energy conversion and management, 124(2016), 607-617. https://doi.org/10.1016/j.enconman.2016.07.007

28. Sukhatme SP, Nayak JK (2013) Solar Energy: - Principles of Thermal Collection and Storage. McGraw Hill Education

29. Agarwal VK, Larson DC (1981) Calculation of top heat loss coefficient of a flat- plate solar collector. Sol Energy 27:69-71. https://doi.org/10.1016/0038-092X(81)90022-0 
30. Swinbank WC (1963) Long-wave radiation from clear skies. Quarterly Journals of Royal Meteorology Society 89:pp, 339-348. https://doi.org/10.1002/qj.49708938105

31. Badiei Z, Eslami M, Jafarpur K; "Performance Improvements in Solar Flat Plate Collectors by Integrating with Phase Change Materials and Fins: A CFD Modeling". Energy,Volume192, February2020,116719.https://doi.org/10.1016/j.energy.2019.116719

\section{Figures}

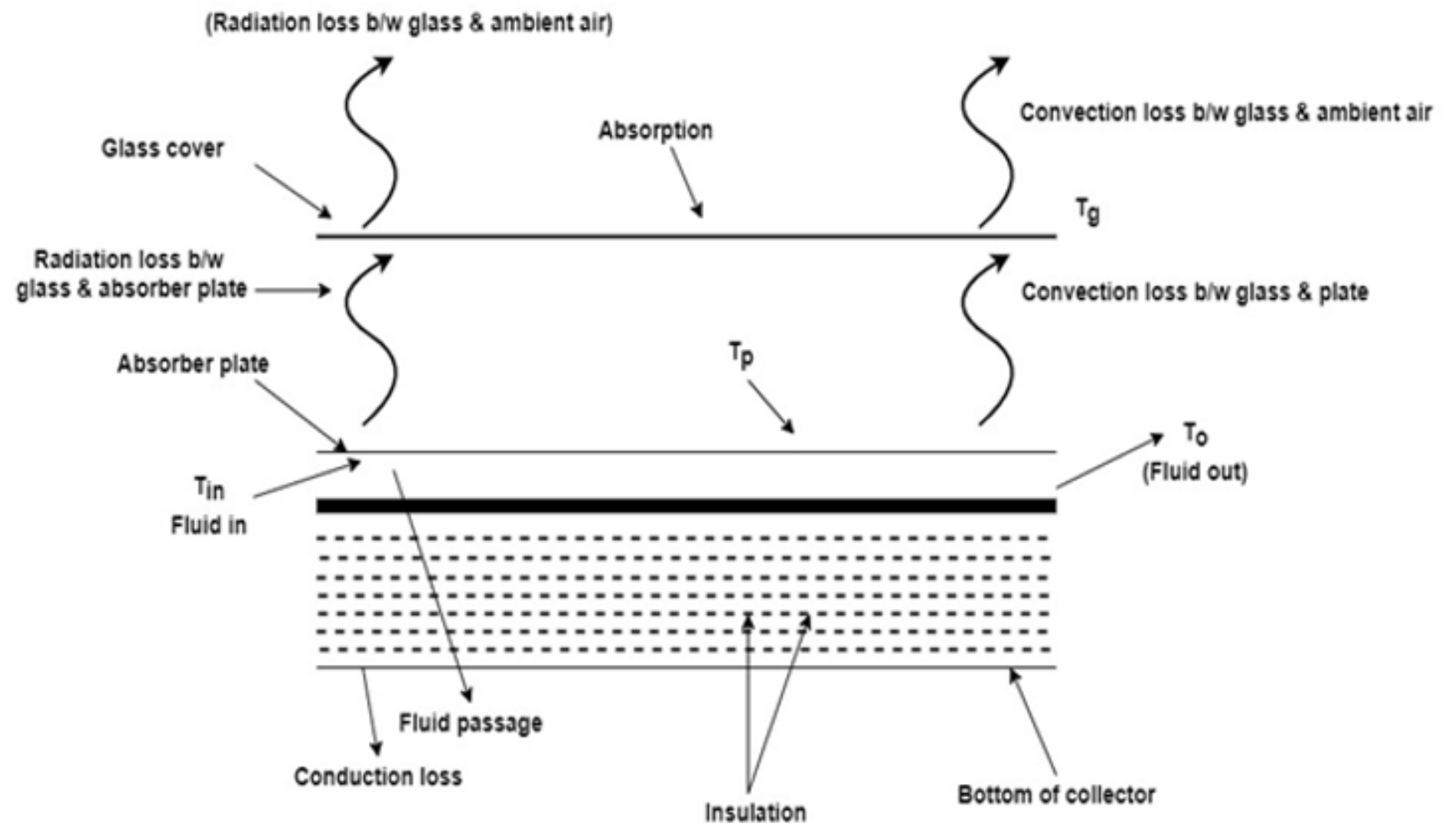

Modes of heat transfer in single glazed flat plate collector

Figure 1

Different kinds of heat transfer and thermal losses occur in flat plate collector. 


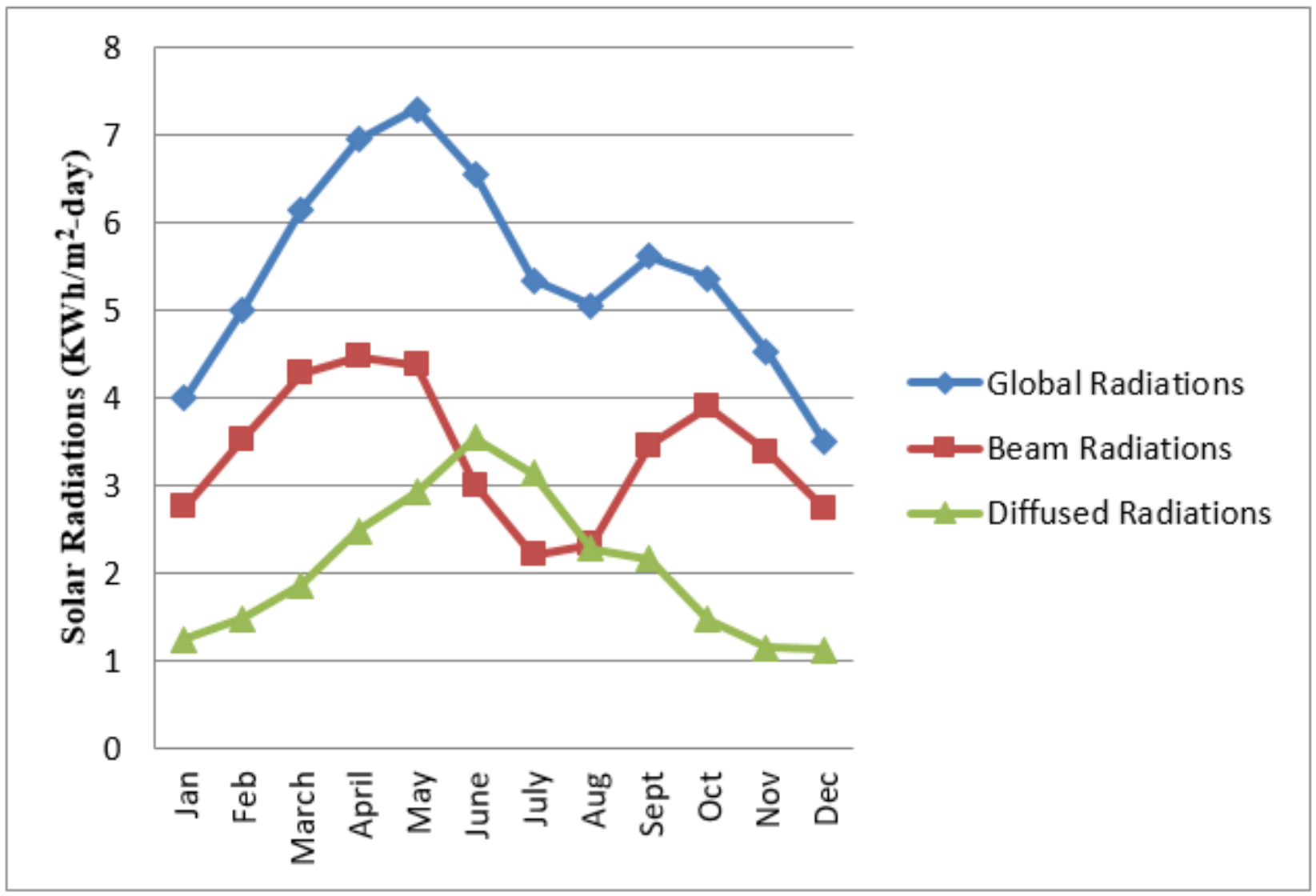

Figure 2

Variations of Solar Radiations per month throughout a year in Delhi (India). 


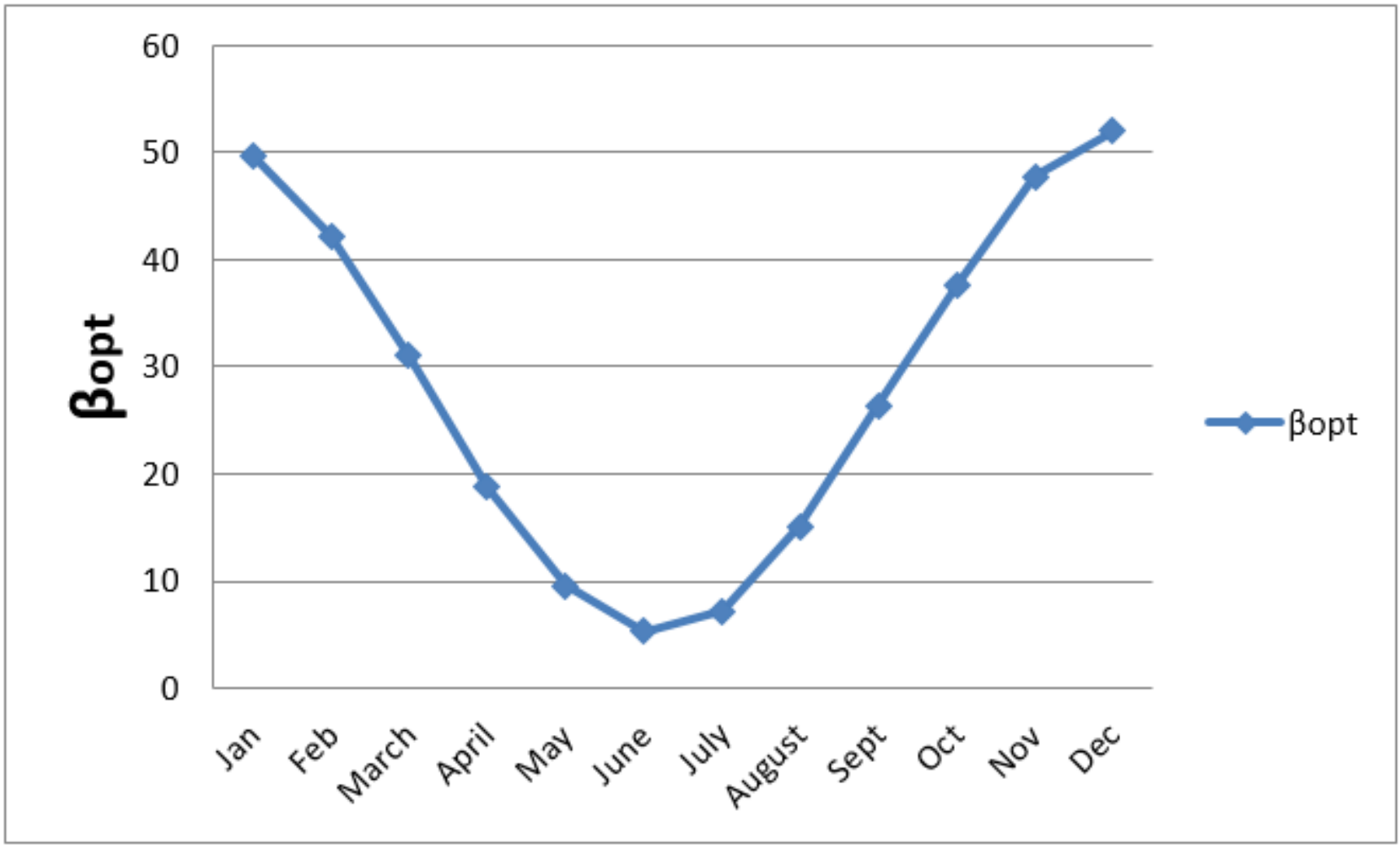

Figure 3

Monthly optimum tilt angle at Delhi (India)

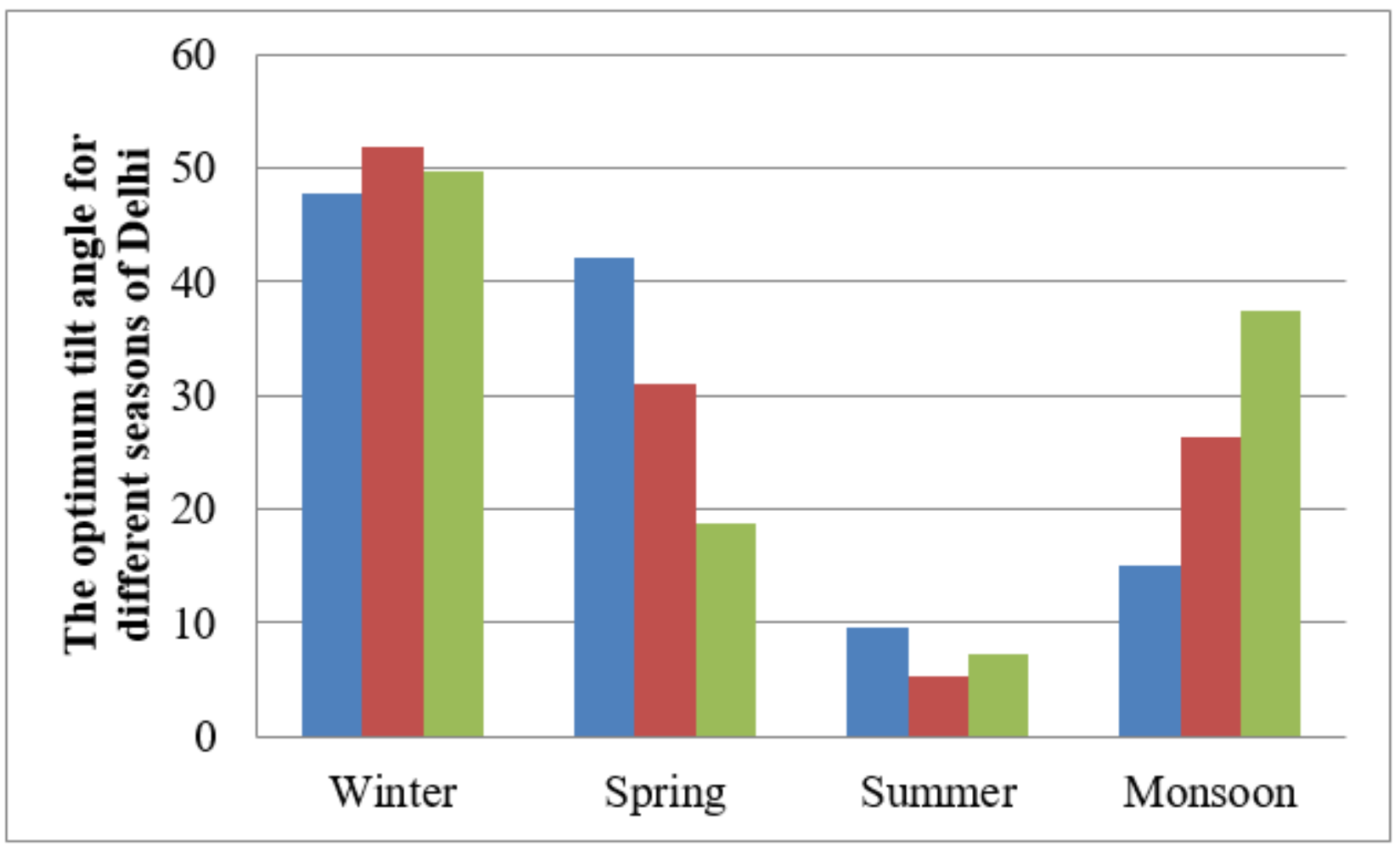


Figure 4

The optimum tilt angle of south-facing plat plate collector located at Delhi under climate conditions encountered in different seasons.

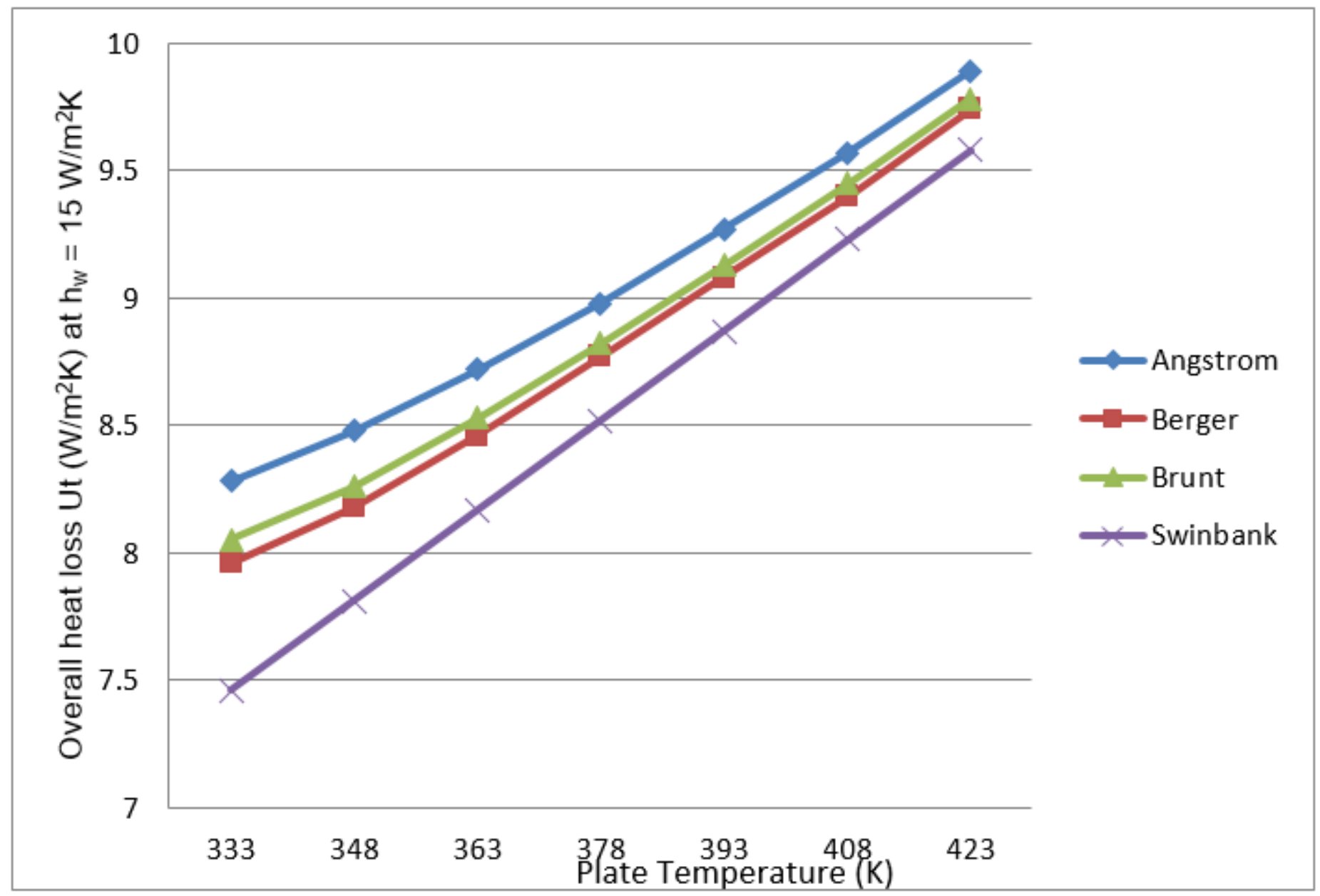

\section{Figure 5}

Variations in values of the overall heat loss coefficient considering the effect of clear sky emissivity. 


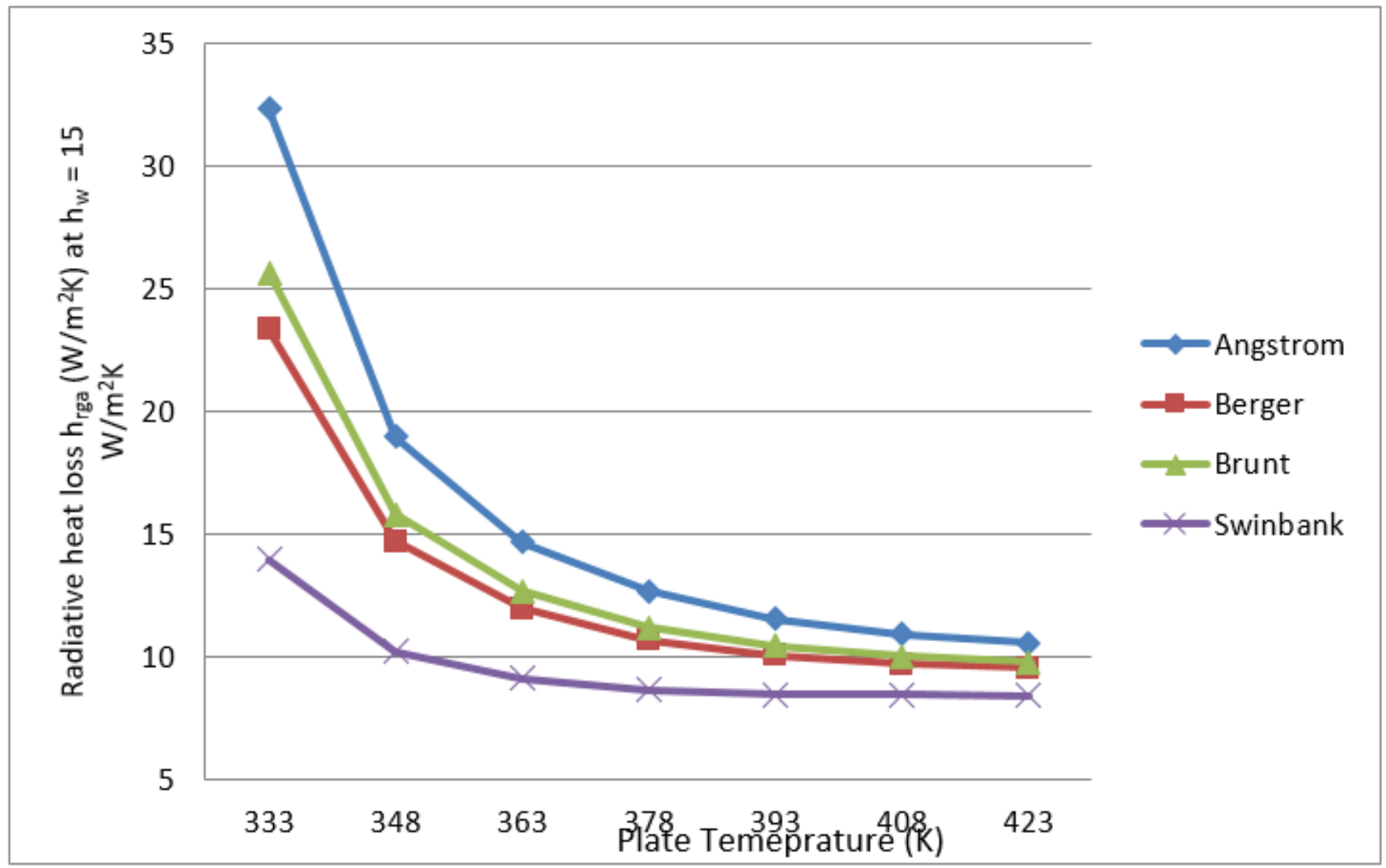

Figure 6

Variations in values of the radiative heat loss coefficient considering the effect of clear sky emissivity. 


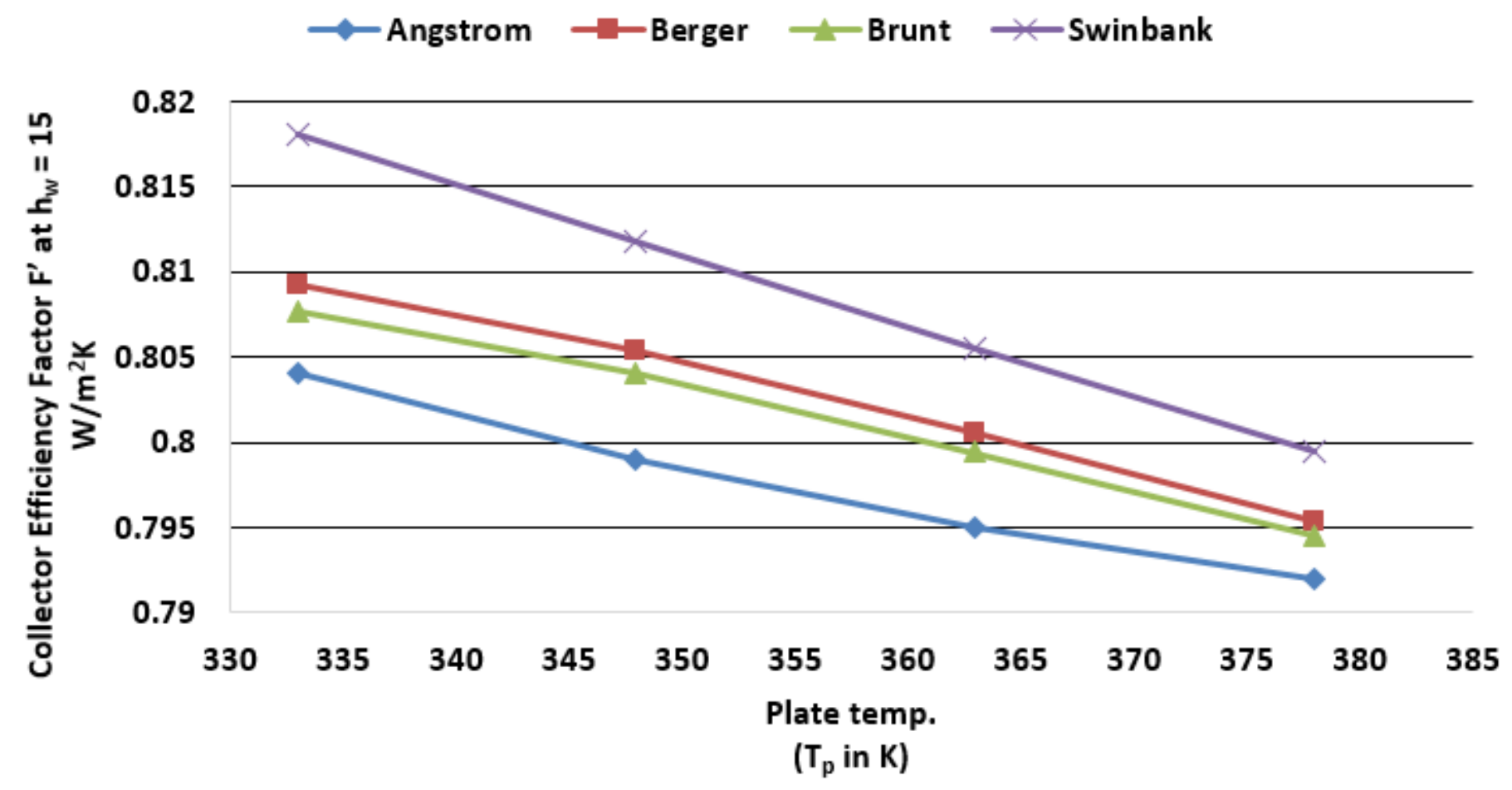

Figure 7

Variation of collector efficiency factor with plate temperature considering the effect of effective black body sky temperature under ambient conditions encountered at Delhi. 


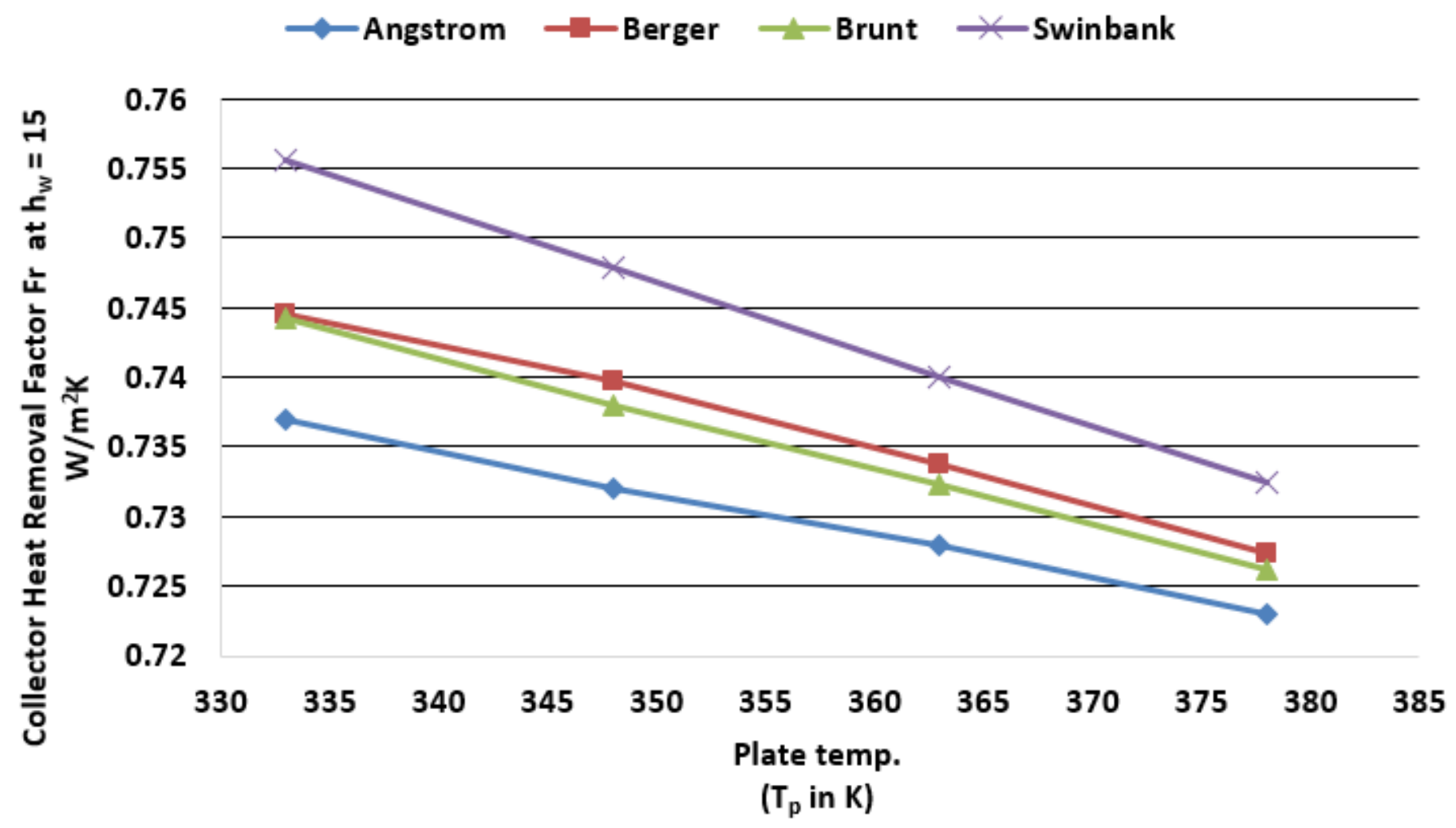

Figure 8

Variation of collector efficiency factor with ambient temperature considering the effect of effective black body sky temperature under ambient conditions encountered at Delhi. 


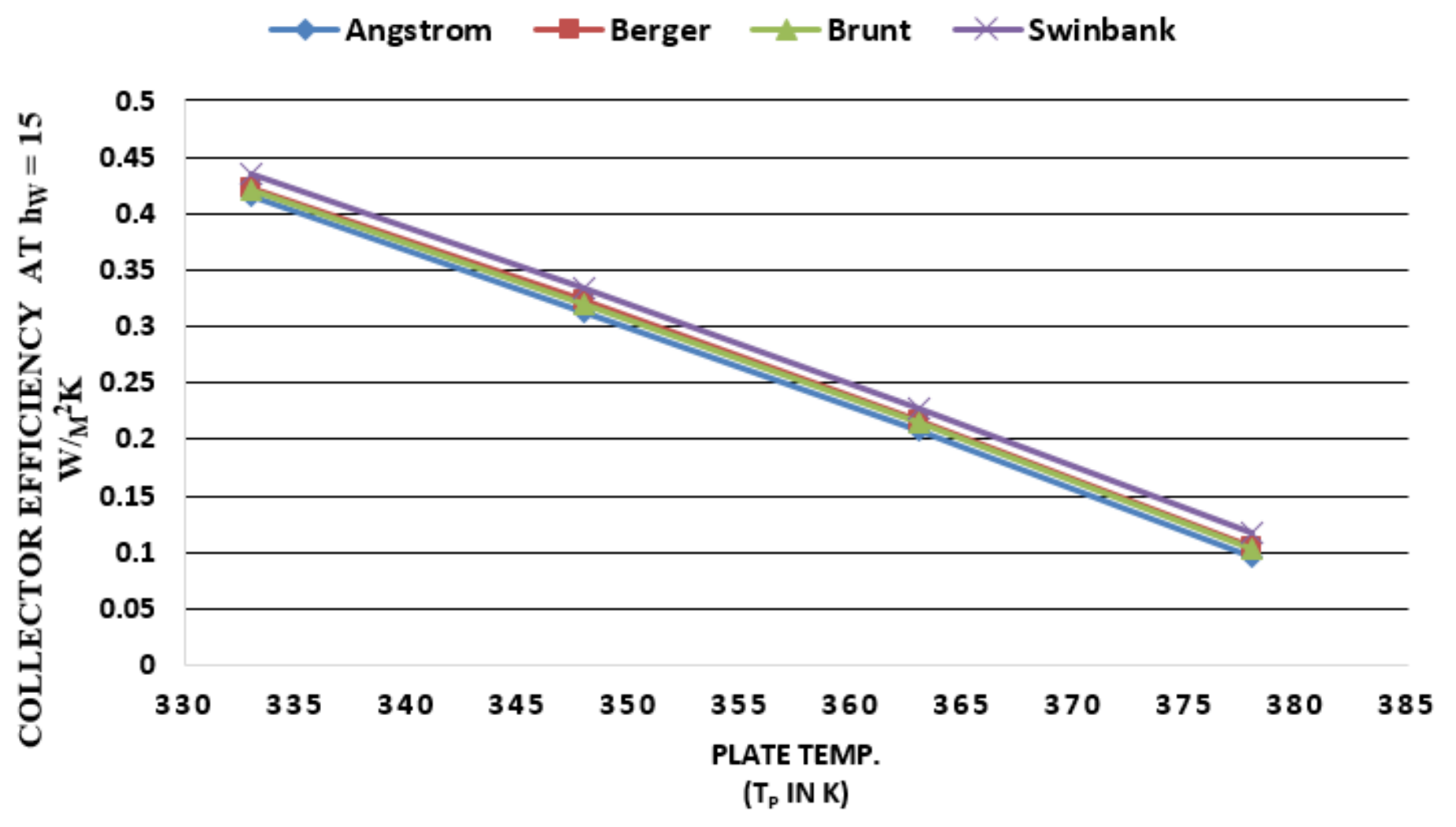

Figure 9

Variation of collector efficiency factor with ambient temperature considering the effect of effective black body sky temperature under ambient conditions encountered at Delhi. 